\title{
Erratum zu: Individual values, cultural embeddedness, and anti-immigration sentiments: explaining differences in the effect of values on attitudes toward immigration across Europe
}

\author{
Eldad Davidov $\cdot$ Bart Meuleman $\cdot$ Shalom H. Schwartz $\cdot$ Peter Schmidt
}

(C) Springer Fachmedien Wiesbaden 2014

In dem Beitrag von Eldad Davidov, Bart Meuleman, Shalom H. Schwartz und Peter Schmidt: „Individual values, cultural embeddedness, and anti-immigration sentiments: Explaining differences in the effect of values on attitudes toward immigration across Europe" (Kölner Zeitschrift für Soziologie und Sozialpsychologie (2014) (Suppl) 66:263-285) wurde irrtümlicherweise der Name des Mitautors Bart Meuleman mit „Bart Meulemann“ falsch abgedruckt. Er lautet korrekt Bart Meuleman. Ebenso lautet sein Geburtsdatum (S. 285) nicht „1965“, sondern „1980“. Die Redaktion bittet den Autor und die Leser um Nachsicht.

\footnotetext{
Die Onlineversion des Originalbeitrages ist erreichbar unter doi:10.1007/s11577-014-0274-5

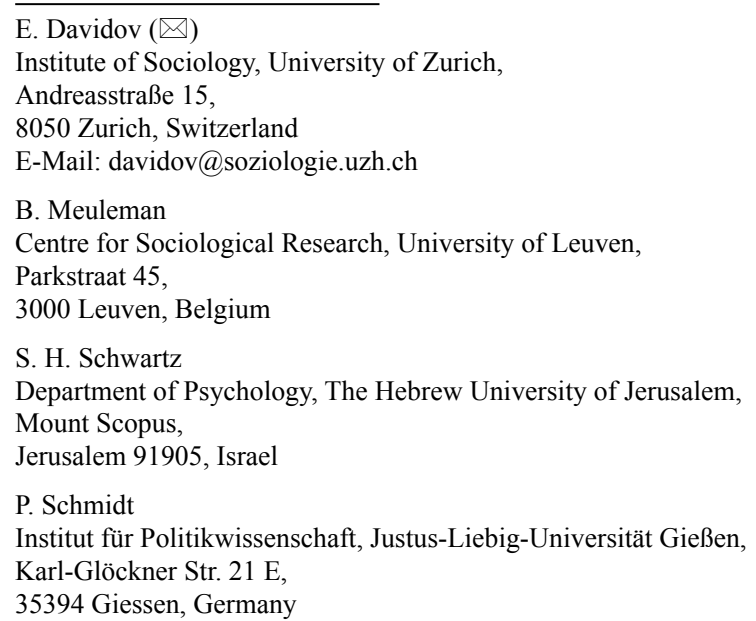

